\title{
Ensefalit Ön Tanısından Zehirlenmeye: Akut Siyanür Zehirlenmesi
}

\section{From Pre-Diagnosis of Encephalitis to Poisoning: Acute Cyanide Poisoning}

\author{
Gülşah DEMiR ${ }^{1}$, Şefika BARDAK¹, Lala DADASHOVA², Necmi Can YÜKSEL ${ }^{2}$, Pelin ELIBOL ${ }^{1}$,
} Alper ÇiÇEK ${ }^{1}$, Emel BERKSOY ${ }^{1}$

'S.B.Ü Tepecik Eğitim Araştırma Hastanesi, Çocuk Acil Bilim Dalı, İzmir, Türkiye

².B.Ü Tepecik Eğitim Araştırma Hastanesi, Çocuk Sağlığı ve Hastalıkları Anabilim Dalı, İzmir, Türkiye

\begin{abstract}
öz
Siyanür bilinen en hızı ölümcül zehirler arasında yer alır. Solunum yolu ve mukoz membranlardan hızla emilir, ayrıca gastrointestinal sistem ve deri yoluyla da absorbe edilebilir. Birçok meyve çekirdeğinde bulunan siyanürün toksik yan etkilere neden olabilmesi için çiğnenerek yutulması gerekir. Nöbet yakınmasıyla çocuk acil servise başvuran üç yaşında bir çocukta konfüzyon, laktik asidoz ve ayrintılı anamnez bilgileri ışığında nörolojik nedenlerden uzaklaşlıp siyanür zehirlenmesi düşünülmüș, hidroksikobalamin (Cyanokit $®)$ intravenöz infüzyonu verilmiş ve hızlı yanıt alınmışıı. Olgu, zehirlenmelerde anamnezin önemine vurgu yaparak nadir görülen ve fatal olabilen siyanür zehirlenmesinin klinik ve laboratuar bulgularına dikkat çekmek amacı ile sunulmuştur.
\end{abstract}

Anahtar Sözcükler: Çocuk, Ensefalit, Siyanür

\begin{abstract}
Cyanide is the fastest and the most fatal poison among other known poisons. It is rapidly absorbed through the respiratory tract and mucous membranes, and can also be absorbed through the gastrointestinal tract and skin. Cyanide can be found as a component in many fruit seeds. If it is chewed and swallowed, it can cause toxic side effects. Confusion and lactic acidosis were determined in a three-year-old child who was admitted to the pediatric emergency room with a complaint of seizure, and according to detailed anamnesis, neurological causes were excluded and cyanide poisoning was diagnosed. An intravenous infusion of hydroxycobalamine (Cyanokit $\AA$ ) was given and rapid response was obtained. We presented this case to call attention to the clinical and laboratory findings of cyanide poisoning, which is rare and can be fatal. Also, we aimed to emphasize the importance of detailed history in intoxications.
\end{abstract}

Key Words: Child, Encephalitis, Cyanide

\section{Giriş}

Siyanid zehirlenmesi nadir görülen ciddi ve ölümcül zehirlenme nedenlerinden biridir. Klinik bulguları özgül değildir ve tanısı zordur. Siyanür (Hidrosiyanik asit, Prussik asit) doğada gaz, SIVı ve katı halde bulunur ve çoğunlukla kimyasal üretim endüstrisinde (sentetik lastik, dericilik, kuyumculuk, fare ve böcek ilaçlarının üretimi, metalürji ve fotoğrafçıllk ,vb) kullanılır. Bir bașka önemli kaynağı da elma, kayısı, șeftali, erik, kiraz gibi meyvelerin tohumlarında bulunan 'amigdalin' adlı glikoziddir. Bu yazıda ensefalit ön tanısından dikkatli anamnez ile kayısı çekirdeği yemeye bağlı siyanür zehirlenmesi tanısı alan üç yaşında erkek hasta, zehirlenmelerde anamnezin önemine ve siyanür zehirlenmesinin klinik ve laboratuar bulgularına dikkat çekmek için sunulmuştur.
DEMIR G

BARDAK S

DADASHOVA L

YÜKSELNC

ÇIÇEK A

BERKSOY E
Çıkar Çatışması / Conflict of Interest: : Tüm yazarlar adına, ilgili yazar çıkar çatışması olmadığııı belirtir.

: 0000-0001-7841-4682 Finansal Destek / Financial Disclosure: Yazarlar bu olgu için finansal destek almadıklarını beyan etmișlerdir.

: 0000-0003-1211-6943

: 0000-0003-2310-7372

(

Atıf yazım sekli / How to cite : Demir G, Bardak S, Dadashova L, Yüksel NC, Elibol P, Ciçek A, Berksoy E. Ensefalit Ön Tanısından Zehirlenmeye: Akut 0000-0002-2195-7421 Siyanür Zehirlenmesi. Türkiye Çocuk Hast Derg 2021;15:542-544.

$0000-0001-5017-4525$

$0000-0002-6831-1353$ 


\section{OLGU}

Daha önceden sağlıklı olan üç yaș erkek hasta acil servise nöbet yakınması ile getirildi. Aktif jeneralize tonik klonik tarzda nöbet geçiren hastaya $0.1 \mathrm{mg} / \mathrm{kg}$ midazolam intravenöz olarak uygulandı ve nöbet kontrol altına alındı. Öyküsünden evde aniden gözlerde kayma, ağızda köpürme ve kasılma şeklinde 2-3 dk süren aralıklı iki defa nöbet geçirdiği, sonrasında acile geldikleri ve hastane kapısında da üçüncü nöbetini geçirmeye başladığı öğrenildi. Yakın zamanda enfeksiyon geçirme ve ateş, travma, ilaç kullanım öyküsü yoktu. Fizik bakısında genel durum: orta, vücut ISISI: 37.5 $\mathrm{C}$, nabı: 108/dk, oksijen satürasyonu: \%98 (oda havasında), kan basıncı: 105/70 mmHg, Glasgow Koma Skalası (GKS): 12/15 (midazolam sonrası) olarak saptandı. Sistemik fizik muayene bulguları olağandı. Meninks irritasyon bulgusu ve patolojik refleks tespit edilmedi. Laboratuar tetkiklerinde lökosit:

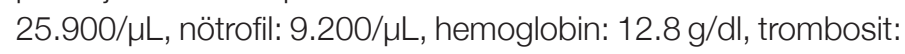
389.000/ $\mathrm{L}$, serum elektrolitleri, kan glikoz düzeyleri normaldi. Kan gazl: Ph: 7.25 pCO2: 21.7 mmHg HCO3: 12.4 mmol/L BE: -16.6 mmol/L Lactat: $12.2 \mathrm{mmol} / \mathrm{L}$ olarak saptandı. Nöbet etiyolojisi için çekilen Kraniyal MRI normaldi. Hastaya intravenöz sıvı desteği, yüksek konsantrasyonda oksijen ve $1 \mathrm{meq} / \mathrm{kg}$ dan intravenöz bikarbonat desteği verildi. Letarjisi devam eden ve göz teması kurmayan hastanın destek tedavilerinin 1. Saatinde bakılan kan gazl; pH: 7.27 pCO2: 24.5 mmHg, HCO3: 13.5 mmol/L, Lactat: $9.8 \mathrm{mmol} / \mathrm{L}$ olarak bulundu. Nöbet geçiren hastada açıklanamayan anyon açıklı metabolik asidoz ve yüksek laktat değerleri zehirlenme olabileceğini düşündürdü. Öykü detaylandırılarak evdeki tüm ilaçların tek tek kontrol edilmesi, eksik ilaç olup olmadığına bakılması, her türlü kimyasal maddenin yerinde olup olmadığının kontrol edilmesi ve son 24 saattir yediklerinin yazılması istendi. Sorgulama sonucunda hastanın sabah saatlerinde bir avuç kadar kayısı çekirdeği yediği ve yarım saat sonra aniden nöbet geçirdiği öğrenildi. Hastaya akut siyanür intoksikasyonu tanısı konularak başvurusundan yaklaşık 4 saat sonra hidroksikobalamin (Cyanokit@) 70 mg/kg intravenöz olarak verildi. Tedaviden bir saat sonra hasta uyanık, bilinci açık, göz kontağı iyi, komutları takip ediyor ve konuşuyordu. Kontrol kan gazl; pH: 7.37, pCO2: 32 mmHg, HCO3: 19.4 mmol/L, Lactat: $1.6 \mathrm{mmol} / \mathrm{L}$ 'di. Acil serviste 24 saatlik monitörlü izlemi boyunca nöbeti tekrarlamayan, vital bulguları stabil seyreden ve laboratuar değerleri normal olan hasta şifa ile taburcu edildi. Hastanın ebeveynlerinden yazılı ve sözlü onam alındı.

\section{TARTIŞMA}

Pek çok meyve çekirdeği, bağırsak bakterileri tarafından hidrojen siyanüre dönüştürülen amigdalin gibi siyanojenik glikozitler içerir $(1,2)$. Toksik yan etkilere neden olması için çok sayıda çekirdeğin ezilerek veya çiğnenerek alınması gerekir. Bu nedenle keşif amaçlı toksik bitki alımından kaynaklanan akut siyanür zehirlenmesi çocuklarda oldukça nadirdir (2). Amigdalin ve laetril (amigdalinin kimyasal bir türü) yetişkinlerde kanser için alternatif tedaviler olarak satılmaktadır ve literatürde 4 yaşında bir çocukta kazara laetril alımından kaynaklanan siyanür zehirlenmesi bildirilmiştir (3). Türkiye'de ise çocuklardaki siyanür zehirlenmesinin çoğunluğu kayısı çekirdeği yeme ile ilişkilidir (4). İnsanlarda öldürücü doz daha düşük miktarlarda bildirilmesine rağmen 1.5 mg/kg olarak kabul edilir (5). Kayısı çekirdeğindeki siyanür içeriği 0.122-4.09 mg/g, ortalama 2.92 mg/g'dır. Böylece tek bir kayısı çekirdeği yaklaşık 0.5 mg siyanür içerir (6). Literatürde üç yaşındaki bir kız çocuğunda üç kayısı çekirdeği çiğneyerek yutması sonrası komaya kadar giden şiddetli intoksikasyon bulguları gözlendiği bildirilmiştir (7). Hastamız ise bir avuç dolusu kayısı çekirdeğini çiğneyerek yedikten yarım saat sonra kusma ve jeneralize tonik klonik vasıflı nöbet geçirmiştir.

Siyanür mitokondriyal sitokromoksidaz enzimini inhibe eder. Hücrenin Adenozin trifosfat (ATP)'yi oluşturmak için anaerobik glikoz metabolizmasına geçmesi gerekir. Anaerobik metabolizma, laktik asit oluşumuna ve metabolik asidoz gelişimine yol açar. ATP hidrolizi tarafından üretilen hidrojen iyonları artık aerobik ATP üretiminde tüketilmez ve bu durum da asidozu şiddetlendirir (8). Serum bikarbonat fazla asidi tamponladıkça azalır ve anyon açığının artmasına neden olur. Oksijene rağmen hücreler oksijeni kullanamaz ve oluşan hipoksi özellikle kardiyovasküler ve merkezi sinir sistemini etkiler. Siyanür, apoptotik hücre ölümünü indükleyerek N-metilD-aspartat (NMDA) reseptörlerini uyarır. Ayrıca inhibe edici nörotransmiter gama-aminobütirik asit (GABA) oluşumundan sorumlu enzim olan glutamik asit dekarboksilazı (GAD) da inhibe eder. Sonuç olarak, GABA seviyeleri düştükçe siyanür nöbet riskini artııı (9-11). Ülkemizde kayısı çekirdeği yenmesine bağlı siyanür zehirlenmesi görülen 13 hasta geriye dönük incelendiğinde hafif zehirlenme belirtilerine ek olarak hastaların izleminde, dört hastada mekanik ventilatör ihtiyacı, iki hastada hipotansiyon, iki hastada koma ve bir hastada konvülsiyonlar şeklinde şiddetli zehirlenme bulguları saptanmıştır (4). Başlangıç semptomları özgül olmadığı için tanı oldukça güçtür. Halsizlik, güçsüzlük, baş ağrısı, baş dönmesi, letarji, konfüzyon, nöbet, koma, hipotansiyon, bradikardi/taşikardi, aritmiler, kardiyovasküler yetmezlik, mide bulantısı, kusma, karın ağrısı, kiraz kırmızısı deri rengi ile nefeste acıbadem kokusu görülebilir. Siyanür zehirlenmesi; ateş, konvülsiyon ve bilinç bulanıklığı ile giden ensefalit vakalarıyla karışabilmektedir (12). Hastamızda da merkezi sinir sistemi etkilerinden tekrarlayan nöbet, letarji, konfüzyon olması öncelikle ensefalit düşündürmüş ve lumbar ponksiyon planlanmıştı. Ancak kan gazında yüksek anyon açıklı metabolik asidoz ve yüksek laktat düzeyi oldukça dikkat çekiciydi. Üstelik hastanın semptomlarının çok akut başlaması, öncesinde ateş, enfeksiyon öyküsünün olmaması da merkezi sinir sistemi enfeksiyon tanısından uzaklaştırmıştı. Renal yetmezlik ve ketoasidozun olmaması nedeniyle ayırıcı tanıda yüksek anyon açıklı metabolik asidoz yapan diğer nedenler, ilaç içme yada kimyasal maruziyet dışlanmıştır. Yetişkinlerde akut siyanür zehirlenmesi olan 11 hastanın ikisinde laktik asid 
düzeyinin> $8 \mathrm{mmol} / \mathrm{L}$ olduğu bildirilmiştir. Laktik asidozun siyanür zehirlenmesi için yüksek oranda spesifik olduğu ifade edilmektedir (13). Bizim hastamızda laktat düzeyi $12.2 \mathrm{mmol} / \mathrm{L}$ olarak saptanmıştır. Literatürde siyanür zehirlenmesi sonrası lökositoz saptanan erişkin hastalar bildirilmiştir (14). Bizim

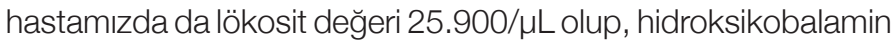
tedavisi sonrası yapılan kontrollerde normal olarak saptanmıştır. Kesin tanı için kan siyanür düzeyi bakıımalıdır (4). Hastamızın kan siyanür düzeyine teknik imkansızlık nedeni ile bakilamamıştır. Ayrıca yapılan çalışmalarda kan siyanür düzeyinin toksisite ile ilişkili olmadığı bildirilmiștir (4).

Siyanür zehirlenmesinde öncelikli tedavi hastaya havayolu, solunum ve dolaşım desteği sağlamaktır. Uygun zamanda gelen hastalar için gastrik dekontaminasyon ve aktif kömür uygulaması yapılmalıdır. Hastamızın bilinci açık olmadığından havayolunu koruyamayacağı öngörülerek ve ilk başvuruda zehirlenme düşünmediğimizden aktif kömür uygulamadık.

Hafif vakalar dışında antidot tedavisi geciktirilmeden uygulanmalıdır. Antidot olarak siyanür antidot kiti (amil nitrit, sodyum nitrit ve sodyum tiyosülfat), Hidroksikobalamin (Cyanokit), Dikobalt EDTA ve 4-dimetilaminofenol kullanılabilir. Küçük çocuklar, yetişkinlere göre daha yüksek fetal hemoglobin konsantrasyonlarına ve daha az methemoglobin redüktaza sahip olduklarından, indüklenen methemoglobinemi, oksijen taşıma kapasitesini tehlikeli derecede düşük seviyelere çekebilir. Nitrit içeren antidotlar hipotansiyon ve methemoglobinemiye neden olur. Methemoglobinemiye bağlı ani kardiyak kollaps gelişebilir. Bu nedenle, hidroksikobalamin siyanür intoksikasyonu için tercih edilen tedavidir ve çocuklarda güvenli kabul edilir. Çocuklarda optimum doz konusunda bir kesinlik olmasa da intravenöz (Cyanokit@) olarak 70mg/kg (maksimum 5 gram ) önerilir (15). Hastamıza $70 \mathrm{mg} / \mathrm{kg}$ dozunda intravenöz hidroksikobalamin (Cyanokit $®$ ) tedavisi uygulanmış olup 1 saat gibi kısa sürede klinik ve laboratuar bulgularda düzelme gözlenmiştir. Hastamızda tedavinin yan etkisi görülmemiştir.

Sonuç olarak nedeni bilinmeyen klinik tablolarda çok iyi bir öykü almak ve şüpheci olup iyi seçilmiş sorularla gerekli bilgileri toplamak çok önemlidir. Akut başlangıçlı bilinç kaybı, artmış anyon açıkı metabolik asidoz ve yüksek laktat düzeyleri varlığında siyanür zehirlenmesi düşünülmeli destek tedavi ile beraber spesifik tedavinin yaşam kurtarıcı olduğu unutulmamalıdır.

\section{KAYNAKLAR}

1. Palmer M, Betz JM. Plants. In: Goldfrank's Toxicologic Emergencies, 9th ed, Nelson LS, Lewin NA, Howland MA, Hoffman RS, Goldfrank LR, Flomenbaum NE (Eds), McGraw-Hill, New York 2011. p.1537.

2. Osterhoudt KC, Burns-Ewald M, Shannon M, Henretig FM. Toxicologic Emergencies. In: Textbook of Pediatric Emergency Medicine, 6th, Fleisher G, Ludwig S (Eds), Lippincott Williams \&Wilkins, Philadelphia 2010. p.1171.
3. Hall $\mathrm{AH}$, Linden $\mathrm{CH}$, Kulig $\mathrm{KW}$, Rumack $\mathrm{BH}$. Cyanide poisoning from laetrile ingestion: role of nitrite therapy. Pediatrics 1986; 78:269-72.

4. Akyildiz BN, Kurtoğlu S, Kondolot M, Tunç A. Cyanide poisoning caused by ingestion of apricot seeds. Ann Trop Paediatr 2010;30:39-43.

5. Suchard JR, Wallace KL, Gerkin RD. Acute cyanide toxicity caused by apricot kernel ingestion. Ann Emerg Med 1998;32:742-4.

6. Holzbecher MD, Moss MA, Ellenberger HA. The cyanide content of laetrile preparations, apricot, peach and apple seeds. J Toxicol Clin Toxicol 1984;22:341-7.

7. Dalkıran T, Kandur Y, Özaslan M, Acıpayam C, Olgar Ş. Role of Hemodialysis in the Management of Cyanide Intoxication From Apricot Kernels in a 3-Year-Old Child. Pediatr Emerg Care 2020;36: e582-4.

8. Mizock BA. Lacticacidosis. Dis Mon 1989; 35:233-300.

9. Tursky T, Sajter V. The influence of potassium cyanide poisoning on the gamma-amino butyric acid level in rat brain. J Neurochem 1962; 9:519-23.

10. Morocco AP. Cyanides. Crit Care Clin 2005;21:691-705.

11. Mohan A, Lee T, Sachdev P. Surviving acute cyanide poisoning: a longitudinal neuropsychological investigation with interval MRI. BMJ Case Rep 2014; 2014: bcr2013203025.

12. Doğan M, Yılmaz C, Kaya A, Caksen H, Taksın G. Cyanide intoxication with encephalitis clinic: a case report. Eastern $\mathrm{J}$ Med 2006;11:22-5.

13. Baud FJ, Borron SW, Mégarbane B, Trout $H$, Lapostolle F, et al. Value of lactic acidosis in the assessment of the severity of the acute cyanid poisoning. Crit Care Med 2002; 30:2044-50.

14. Dooroshi G, Dorostkar A, Rahimi A, Zoofaghari S. An Unusual Acute Cyanide Intoxication. Adv Biomed Res 2020; 9: 42.

15. Mintegi S, Clerigue N, Tipo V, Ponticiello E, Lonati D, Burillo-Putze $\mathrm{G}$, et al. Pediatric cyanide poisoning by fire smoke inhalation: a European expert consensus. Toxicology Surveillance System of the Intoxications Working Group of the Spanish Society of Paediatric Emergencies. Pediatr Emerg Care 2013; 29:1234. 